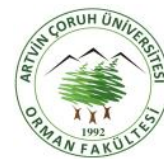

\title{
Yaban mersininin (Vaccinium myrtillus L.) farklı çözücü ekstraktlarındaki antioksidan ve antimikrobiyal aktivitelerinin belirlenmesi
}

\section{Determination of antioxidant and antimicrobial activities of bilberry (Vaccinium myrtillus L.) extrackts in different solvents}

\author{
Şule CEYLAN ${ }^{1}$, Özlem SARAL ${ }^{2}$, Mehmet ÖZCAN³ , Burhan HARŞIT ${ }^{4}$ \\ ${ }^{1}$ Artvin Çoruh Üniversitesi, Sağlık Bilimleri Fakültesi, İş Sağlığı ve Güvenliği Bölümü, Artvin, Türkiye \\ ${ }^{2}$ Recep Tayyip Erdoğan Üniversitesi, Sağlık Yüksek Okulu, Beslenme ve Diyetetik Bölümü, Rize, Türkiye \\ ${ }^{3}$ Hacettepe Üniversitesi, Tıp Fakültesi, Tıbbi Biyokimya Anabilim Dalı, Ankara, Türkiye \\ ${ }^{4}$ Artvin Çoruh Üniversitesi, Orman Fakültesi, Orman Endüstri Mühendisliği Bölümü, Artvin, Türkiye
}

\section{Eser Bilgisi / Article Info}

Araştırma makalesi / Research article

DOI: 10.17474/artvinofd.271088

Sorumlu yazar / Corresponding author

Şule CEYLAN

e-mail: sceylan@artvin.edu.tr

Geliş tarihi / Received

03.06.2016

Düzeltme tarihi / Received in revised form

03.08.2016

Elektronik erişim / Online available

30.11.2016

Anahtar kelimeler:

Yaban Mersini

Antioksidan aktivite

Antimikrobiyal aktivite

Toplam polifenol

DPPH

FRAP

\section{Keywords:}

Bilberry

Antioxidant activity

Antimicrobial activity

Total polyphenol

DPPH

FRAP

\begin{abstract}
Özet
Bu çalışmada Giresun ilinde yetişen yaban mersininin (Vaccinium myrtillus L.) meyve ve yaprağı, hem yaş hem de kurutulmuş halinin dört farklı çözücüdeki ekstraktları (etanol, aseton, su ve dietil eter) ayrı ayrı incelenmiştir. Bitkisel ürünlerin antioksidan kapasitelerini değerlendirmek için çeşitli yöntemler kullanılmıştır. Bu yöntemler, FRAP ( $\mathrm{Fe}^{3+}$ Indirgeme Antioksidan Gücü), DPPH• giderme ve toplam polifenol tayinini içermektedir. FRAP tayini yönünden, ekstraktların indirgeme güçlerinin aseton > etanol > su > dietil eter şeklinde sıralandığı görülmüştür. Serbest radikal giderme aktivitesi antioksidan sonuçlarına göre, kurutulmuş halde alınan örneklerin ekstraktları, yaş haline göre daha iyi düzeyde DPPH radikali giderme aktivitesi sergilemiştir ve en yüksek aktiviteyi çözücüsü etanol olan kuru yaprak ekstraktının gösterdiği bulunmuştur. Toplam fenolik madde miktarı tayinine göre ise, ekstraktlarda var olan fenolik madde içeriklerinin gallik asit eşdeğeri cinsinden $0.121 \pm 0.00-19.484 \pm 1.85 \mathrm{mg} / \mathrm{g}$ aralığında değiştiği ve en yüksek aktiviteyi yaban mersininin çözücüsü su olan kuru yaprak ekstraktının gösterdiği belirlenmiştir. Aynı zamanda bitki ekstrelerindeki antimikrobiyal aktivite, Agar disk difüzyon yöntemi kullanılarak tespit edilmiştir. Yaban mersini bitkisi ile hazırlanan ekstraktlar arasında, çözücüsü etanol ve aseton olan ekstrakların test mikroorganizmalarının çoğuna karşı iyi derecede aktivite gösterdiği bulunmuştur.
\end{abstract}

\begin{abstract}
In this study, both fresh and dried fruit, leaves extracts of bilberies (V. myrtillus L.) growed in Giresun have been investigated in four different solvents (ethanol, acetone, water and diethyl ether). Several methods have been utilized to evaluate the antioxidant capacity of plant materials. These methods include FRAP (ferric ion reducing antioxidant power), DPPH $\bullet$ (free radical) and analysis of total polyphenol. The reducing powers of extract have been acetone $>$ ethanol $>$ water $>$ diethyl ether respectively. According to free radical scavenging activity results, the extracts obtained dried samples have had better DPPH radical scavenging results than fresh ones and the dried leaves extracts in ethanol have showed the highest activity. According to analysis of total phenol, the phenolic contents in extracts have been determined as gallic acid equivalent ranging from $0.121 \pm 0.00$ to $19.484 \pm 1.85$ $\mathrm{mg} / \mathrm{g}$ and the dried bilberry leaves extracts in water have showed the highest activity. In addition, antimicrobial activities of plant extracts have been determined by the agar disk diffusion method. The extracts with ethanol and acetone among all bilberry extract have been showed a good degree of activity against most of tested microorganisms.
\end{abstract}

\section{Giriş}

Insanlar ilk çağlardan beri bitkileri tıbbi amaçlar için kullanmaktadır. Hastalıklar korunmak için çeşitli ilaçlar geliştirilmeden önce çok çeşitli bitki türleri ilaç amacıyla kullanılmıştır (Abay 2006). Modern ilaç endüstrisi geliştikten sonra birçok sentetik olarak üretilen ilaca karşılık son yıllarda özellikle endüstrileşmiş ülkelerde bitki kökenli ilaçların kullanımına yönelik eğilimin artığı görülmektedir (Ünal 2006).
Hücrelerde gerçekleşen biyokimyasal reaksiyonlar sonucu veya birçok ekzojen etkenlerden dolayı hücresel canlılık için zararlı serbest radikaller oluşur (Akkuş 1995). Serbest radikallerden kaynaklanan oksidatif stres ile hücre içerisindeki birçok hayati bileşiğin oksidasyonuna neden olur. Protein oksidasyonu, lipit peroksidasyonu ve DNA hasarı oluşumu bu tür oksidatif reaksiyonlar sonucu meydana gelmektedir. (Kil vd. 2009). Son yıllarda yapılan çalışmalarda serbest radikallerin insan sağlığı olan 
zararları üzerine odaklanılmış, diyabet, arteroskleroz, yaşlanma ve kanser gibi çeşitli hastalıkların oluşmasında etkisinin büyük olduğu gösterilmiştir (Akagün 2009). Canlıların serbest radikallerden kaynaklı oksidatif stresle mücadele edebilmesi için antioksidatif koruma sistemleri vardır. Fakat bazı antioksidatif koruma sistemlerin bazı durumlarda iyi çalışmamasından dolay serbest radikallerin maruziyeti artmaktadır. Bu nedenle oksidatif stresle mücadele için takviye ilaç veya besinlere ihtiyaç duyulmaktadır.

Antioksidanlar vücuda zarar veren serbest radikallerin etkisiz hale getirilmesinde kullanılan molekülerdir. Serbest radikallerin etkisiz hale gelmesiyle vücuttaki birçok biyomolekül zarar görmeden işlevini doğru şekilde yerine getirmesi sağlanır. Böylece patalojik durumların oluşma riski aza indirgenir (Akkuş 1995). Daha önce yapılan çalışmalarda birçok bitkisel ekstraktların fitokimyasal bileşik içeriklerinin sayesinde kuvvetli antioksidan ve antimikrobiyal aktiviteye sahip olduğu gösterilmektedir (Kırca 2007).

Yaban mersini, Türkiye'de özellikle Doğu Karadeniz Bölgesi'nde yetiştirilen üzümsü bir meyvedir. Yaban mersini yüksek antioksidan kapasiteye sahip olup, bol miktarda fenolik bileşen içermektedir. Kanser, kardio ve serebrovasküler hastalıklar, atherosklerosis ve diabet gibi bazı kronik hastalıklara karşı koruyucu etkisi yüksek antioksidan kapasitesine bağlanmaktadır (Wu ve ark. 2002). Küçük taneli birçok meyve üzerinde yapılan analizlerin sonuçlarına göre; yabani yaban mersinlerinin belirlenen oksijen radikallerini absorbe etme kapasitesiyle en yüksek antioksidant etkiye sahip oldukları saptanmıştır (Atalay ve ark. 2003).

Fenolik bileşikler bitkilerin içerisinde en bol bulunan bileşenler olmasıyla birlikte bitki aleminde 6.000'den daha fazla fenolik bileşiğin buluduğu ifade edilmektedir. (Bravo, 1998). Fenolik bileşikler, bitkilerin çiçek, kök, gövde, meyve, sebze, kuruyemiş ve tohum gibi kısımlarında farklı oranlarda bulunan ve doğal yolla sentezlenen maddelerdir (Wollgast ve Anklam 2000). Birçok fenolik bileşiğin potansiyel olarak antioksidan, antikarsinogenik, antimutajenik, antimikrobiyel, antiviral ve antiinflematuar özelliklere sahip olduğunu gösteren çalışmalar literatürde mevcuttur (Almaraz ve ark. 2007; Evers ve ark. 2005; Harris ve ark. 2006).

Son yıllarda, antibiyotiklerin bilinçsizce ve aşırı kullanımlarından dolayı bulaşıcı hastalık ve enfeksiyonlarına neden olan birçok mikroorganizma türünün antibiyotiklere karşı direnç geliştirdiği bilinmektedir (Janovska vd. 2003, Hussain 2011). Tedavi edici mevcut antibiyotiklere karşı mikroorganizmaların geliştirdiği direncin artması, araştırmacıları yeni antibiyotik etkisi olan bileşiklerin bulunmasına yöneltmektedir (Singh vd. 2011).

Bitkilerde bulunan fenolik bileşiklerin ekstraksiyonu; çözücüler, sıcaklık, ekstraksiyon zamanı, partiküllerin büyüklüğü, örnek cinsi ve ekstraksiyon metodları gibi birçok faktör tarafından etkilenmektedir. Bu nedenle bu çalışmada Giresun ilinde yetişen Yaban mersininden elde edilen değişik çözücülerdeki ekstraktların antioksidan ve antibakteriyal etkilerinin belirlenmesi amaçlanmıştır.

\section{MATERYAL VE YÖNTEM}

\section{Örneklerin hazırlanması}

Çalışmada kullanılan Yaban mersini meyvesi ve yaprakları haziran ayında Giresun ilinden elde edilmiştir. Taze meyve ve yapraklardan 10 gramlık örnekler alınıp taze ve +40 ${ }^{\circ} C^{\prime}$ de etüvde kurutulmuş (sabit tartıma gelinceye kadar) olarak iki farklı şekilde hazırlanmıştır. Taze ve kuru örnekler mekanik öğütücü ile parçalandıktan sonra ayrı ayrı olacak şekilde üzerlerine 100 'er $\mathrm{mL}$ etanol, aseton, su ve dietil eter çözücüleri eklenmiştir. Ekstraksiyon işlemi her bir örnek için ayrı olmak üzere 24 saat boyunca çalkalayıcıda karıştırılarak gerçekleştirilmiştir. Daha sonra adi süzgeç kağıdı kullanılarak süzülmüş ve belli hacimlere ilgili çözücüleri ile tamamlanmıştır. Daha sonra elde edilen ekstraklar antioksidan ve antimikrobiyal aktivite analizleri için $+4{ }^{\circ} \mathrm{C}^{\prime}$ de muhafaza edilmiştir.

\section{Test bakterileri}

Bu araştırmada kullanılan bakteri suşları Refik Saydam Hıfzıssıhha Enstitüsünden (Ankara) temin edilmiştir. Bu suşlar; Bacillus subtilis (B. Subtilis), Candida albicans (C. albicans) ATCC60193, Enterococcus faecalis (E. faecalis) ATCC29212, Escherichia coli (E. coli) ATCC35218, Mycobacterium smegmatis (M. smegmatis) ATCC607, 
Pseudomonas aeruginosa (P. aeruginosa) ATCC43288, Staphylococcus aureus (S. aureus) ATCC25923, Saccharomyces cerevisiae (S. cerevisia) RSKK 251, Yersinia pseudotuberculosis (Y. pseudotuberculosis) ATCC911.

Kullanılan yöntemin kontrolü ve kullanılan bakteri türlerinin hassasiyetinin için Ampisilin, standart olarak Flukonozol ve Streptomisin antibiyotik diskleri kullanımıştır.

\section{Antioksidan tayinleri}

\section{Toplam polifenol tayini}

Tüm örneklerin etanol, aseton, su ve dietil eter ekstralarındaki toplam polifenolik madde içerikleri FolinCiocalteu reaktifi (FCR) kullanılarak belirlenmiştir (Singleton ve Rossi, 1965). FCR reaktifi fosfomolibdik ( $\left.\mathrm{H}_{3} \mathrm{PMo12O} 40\right)$ ve fosfotungustik ( $\left.\mathrm{H}_{3} \mathrm{PW} 12 \mathrm{O} 40\right)$ asitlerin karışımından oluşturulup fenolik bileşiklerin oksidasyonu sırasında mavi renkli bileşiklere dönüşür. Bu renk değişimleri 760 nm'de spektrofotometrede takip edilir ve polifenolik bileşik miktarı ile orantılıdır. Genel olarak polifenol miktarı kateşol ekivalenti veya gallik asit şeklinde ifade edilir. Bu çalışmada polifenol miktarı gallik asit ile hazırlanan standart grafikten yararlanılarak tayin edilmiştir.

\section{FRAP ( Fe3+ indirgeme Gücü ) metodu}

Demir iyonu indirgeyici antioksidan güç olarak ifade edilen FRAP metodu, Fe(III)-TPTZ bileşiğinin antioksidanlar eşliğinde mavi renge sahip Fe(II)-TPTZ bileşiğine indirgenmesi ve bu bileşiğin maksimum absorbansı 593 nm'de vermesi temeline dayanır. Bu yöntemde absorbans sonuçları $4 \mathrm{dk}$ boyunca izlenir. Sonuçlar troloks eşiti olarak ifade edilir (Benzie and Strain, 1996).

\section{DPPH radikali temizleme aktivitesi}

DPPH (2,2-difenil-1-pikrilhidrazil) serbest radikal temizleme yönteminde, kararlı ve sentetik bir radikal olan DPPH kullanılır ve antioksidanın bu serbest radikali yakalama yeteneği ölçülerek antioksidan aktivite tanımlanır. DPPH, koyu mor renkte bir radikaldir. Antioksidandan bir proton alarak renksiz $\alpha, \alpha$-difenil- $\beta$ pikrilhidrazil molekülüne dönüşür. Antioksidan madde tarafından indirgenmesi sonucu rengi açıı.ır. En yaygın olarak kullanılan dekolarizasyon test metodu $517 \mathrm{~nm}$ dalga boyunda DPPH'in antioksidan madde ile reaksiyonunun absorbansının ölçülmesidir (Frankel ve Meyer 2000). Bu çalışmada eşit hacimlerde olacak şekilde (750 $\mu \mathrm{L}$ ) numune çözeltileri ve DPPH çözeltisi karıştırılıp 50 dakika oda sıcaklığında inkübasyona bırakıldıktan sonra absorbanslar $517 \mathrm{~nm}$ 'de okunmuştur. Numunenin çözüldüğü çözücü ve DPPH çözeltisi kör olarak kullanılmıştır. Elde edilen absorbanslara karşılık gelen konsantrasyon grafiği çizilmiş ve $\mathrm{IC}_{50}$ değerleri $\mathrm{mg} / \mathrm{mL}$ cinsinden hesaplanmıştır.

\section{Antimikrobiyal aktivitenin belirlenmesi}

Maya suşları, Sabouraud Dextrose Broth'a (SDB) (Difco) aşılanarak $25 \pm 0.1{ }^{\circ} \mathrm{C}^{\prime}$ de 48 saat; bakteri suşları Nutrient Broth'a (Difco ) aşılanarak (NB) $37 \pm 0.1{ }^{\circ} \mathrm{C}^{\prime}$ de 24 saat; süreyle inkübasyona bırakılır. Mueller Hinton Agara (MHA, Oxoid)(15ml) erlen mayer kaplarında sterilize edilip 45-50 ${ }^{\circ} C^{\prime}$ ye kadar soğutulur. Sabouraud Dextrose Agar (15 ml) (SDA) da yoğunluğu $10.5 \mathrm{ml}$ de olan 48 saatlik maya kültüründen $0.01 \mathrm{ml}$, bakteri yoğunluğu $\mathrm{ml}$ de 106 bakterinin 24 saatlik buyyon kültüründen $0.01 \mathrm{ml}$ alınarak aşılama gerçekleştirilir (NCCLS 2000).

İyi bir çalkalama gerçekleştirildikten sonra steril petri kaplarına (9.0 cm çapındaki) $15 \mathrm{ml}$ besiyerinin steril pipetlerle petri kutusuna homojen olacak şekilde dağıtıImıştır. (Bauer ve ark. 1966; NCCLS, 2000; Bradshaw, 1992; Toroglu, 2007). Ekstre emdirilmiş diskler katı hale gelen agar üstüne hafifçe baskı uygulanarak konulmuştur. Dikkatlice hazırlanmış olan petri kutuları $4{ }^{\circ} \mathrm{C}$ 'de yaklaşık 1-2 saat bekletilir. Ondan sonra maya aşılanan plaklar $25 \pm 0.1{ }^{\circ} \mathrm{C}$ de 48 saat, bakteri aşılanan plaklar ise $37 \pm 0.1$ ${ }^{\circ} \mathrm{C}$ 18-24 saat inkübe edilmiştir (Bradshaw, 1992; Toroglu, 2007; Collins ve ark. 1989). Gerekli bu bekleme süreleri sonunda besi yeri üzerinde meydana gelen inhibisyon konsantrasyonları $\mu \mathrm{g} / \mathrm{mL}$ şeklinde ölçülmüştür ve sadece aktivite gösteren değerler Tablo 3'de gösterilmiştir. 


\section{BULGULAR VE TARTIŞMA}

\section{Antioksidan aktivite}

Yaban mersini türleri antioksidan içeriği en yüksek olan meyvelere sahip türlerdir. Yapraklarından ve kurutulmuş meyvelerinden çay yapılarak ya da taze meyve olarak marketlerde satılmaktadır. Son zamanlarda gerçekleştirilen çalışmalara göre yaban mersininin yaşlanmayı önlediğini yani anti aging özelliğe sahip olduğu ve hafıza kayıplarını engellediği belirlenmiştir (Çelik 2006).

Yaban mersinleri yüksek miktarda fenolik bileşik içermektedir. Bu yüzden de yüksek antioksidan aktiviteye sahiptirler. Yaban mersininin bu denli değerli olması, kültürlerinin de üretimine geçilip daha kolay ulaşılır hale gelmesi bu meyveye olan ilgiyi artırmıştır.
Giresun yöresinde yetişen yaban mersini türlerinin antioksidan içeriğin tespiti için yapılan bu çalışmada yaban mersini meyvesi ve yaprağı yaş ve kurutulmuş halde incelenmiştir. Meyvede ve yaprakta toplam Polifenol, FRAP ve DPPH antioksidan aktivite analizleri yapılmış ve bu testlerde spektrofotometrik yöntemler kullanılmıştır. Spektrofotometrik yöntemler doğal ham maddelerin standardizasyonu için sıklıkla kullanılmaktadır.

Etanol, aseton, su ve dietil eter ekstraktlarını mg gallik asit / g numune cinsinden toplam polifenol miktarı Tablo 1'de gösterilmiştir. Elde edilen sonuçlara göre yaban mersini meyve ve yapraklarında toplam polifenol içeriklerine bakıldığında en yüksek içerik yaban mersininin yaş meyvesinin aseton ekstraktında, kuru meyvesinin etanoldaki ekstraktında ve yaban mersininin kuru yaprağının su ekstraktında olduğu görülmüştür.

Tablo 1. Yaban mersini ekstraktlarının toplam polifenol içerikleri

\begin{tabular}{lllll}
\hline \multirow{2}{*}{ Ekstrakt Çözücüleri } & \multicolumn{4}{c}{ Toplam Polifenol (mg gallik asit/g numune )(X \pm SS) } \\
\cline { 2 - 5 } Etanol & Kuru Yaprak & Kuru Meyve & Yaş Meyve & Yaş Yapak \\
Aseton & $8.044 \pm 0.93$ & $11.457 \pm 0.46$ & $2.391 \pm 2.07$ & $2.780 \pm 0.50$ \\
Su & $2.312 \pm 0.44$ & $0.561 \pm 0.21$ & $12.136 \pm 1.68$ & $2.406 \pm 0.04$ \\
Dietil eter & $19.484 \pm 1.85$ & $0.594 \pm 0.16$ & $1.229 \pm 0.19$ & $2.498 \pm 0.20$ \\
\hline
\end{tabular}

Etanol, aseton, su ve dietil eter ekstraktlarının FRAP metodu ile belirlenen antioksidan aktiviteleri $\mu \mathrm{mol}$ Troloks /g numune olarak Troloks eşdeğeri (TEAP değeri) cinsinden Tablo 2'de gösterilmiştir. FRAP metodu ile belirlenen antioksidan aktiviteleri incelendiğinde yaban mersininin yaş meyvesinin aseton ekstraktında, kuru meyvesinin etanoldaki ekstraktında ve yaban mersininin kuru yaprağının su ekstraktındaki antioksidan aktivite değerlerinin diğer ekstraksiyon yöntemlerine göre önemli ölçüde yüksek olduğu tespit edilmiştir. Aynı zamanda extraktların indirgeme güçleri aseton > etanol > su > dietil eter gibi sıralama gösterdiği bulunmuştur.

Tablo 2. Yaban mersini ekstraktlarının FRAP metoduyla belirlenen antioksidan sonuçları

\begin{tabular}{|c|c|c|c|c|}
\hline \multirow{2}{*}{$\begin{array}{l}\text { Ekstrakt } \\
\text { Çözücüleri }\end{array}$} & \multicolumn{4}{|c|}{ FRAP Tayini ( $\mu \mathrm{mol}$ Troloks /g numune) (X士SS) } \\
\hline & Kuru Yaprak & Kuru Meyve & Yaş Meyve & Yaş Yapak \\
\hline Etanol & $24.323 \pm 4.126$ & $153.051 \pm 31.685$ & $9.272 \pm 0.403$ & $9.452 \pm 0.112$ \\
\hline Aseton & $19.722 \pm 1.945$ & $10.505 \pm 1.089$ & $183.762 \pm 31.485$ & $15.585 \pm 0.281$ \\
\hline Su & $652.049 \pm 49.439$ & $8.710 \pm 0.959$ & $12.789 \pm 1.107$ & $8.586 \pm 0.791$ \\
\hline Dietil eter & $0.115 \pm 0.010$ & $1.958 \pm 0.013$ & $0.536 \pm 0.056$ & $2.772 \pm 0.526$ \\
\hline
\end{tabular}

Yaban mersini ekstraktlarının ve Troloks standardı için uygulanan DPPH radikal temizleme aktivitesi testinden elde edilen IC $_{50}$ değerleri Şekil 1 'de gösterilmiştir. DPPH radikal temizleme aktivitesi sonuçları incelendiğinde kuru yaprak etanol eksktraktının en etkin $\mathrm{IC}_{50}$ konstantrasyonuna $(0.55 \mathrm{mg} / \mathrm{ml})$ sahip olduğu görülmüştür. 


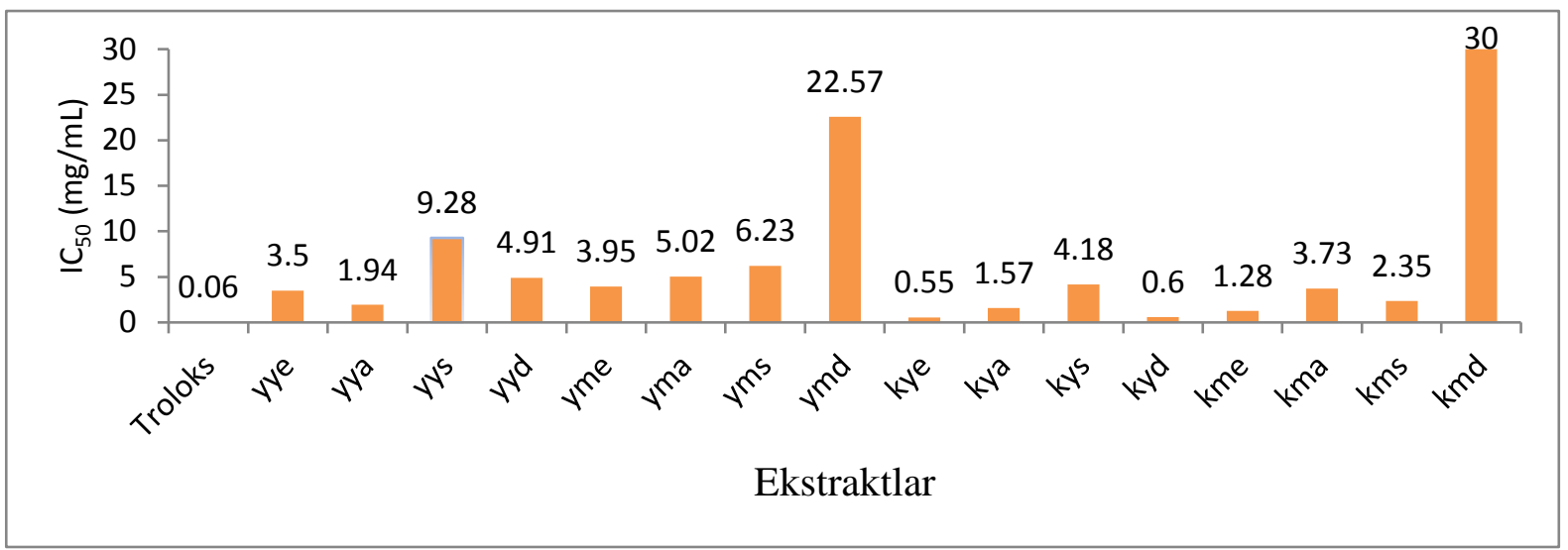

Şekil 1. DPPH radikal temizleme aktivitesi test sonuçları (Troloks: standart, yye: yaş yaprak etanol ekstraktı, yya: yaş yaprak aseton ekstraktı, yys: yaş yaprak su ekstraktı, yyd: yaş yaprak dietil eter ekstraktı, yme: yaş meyve etanol ekstraktı, yma: yaş meyve aseton ekstraktı, yms: yaş meyve su ekstraktı, ymd: yaş meyve dietil eter ekstraktı, kye: kuru yaprak etanol ekstraktı, kya: kuru yaprak aseton ekstraktı, kys: kuru yaprak su ekstraktı, kyd: kuru yaprak dietil eter ekstraktı, kme: kuru meyve etanol ekstraktı, kma: kuru meyve aseton ekstraktı, kms: kuru meyve su ekstraktı, kmd: kuru meyve dietil eter ekstraktı)

\section{Antimikrobiyal aktivite}

Tablo 3' de gösterilen ve Agar disk difüzyon yöntemi kullanılarak tespit edilen antimikrobiyal aktiviteye göre, yaban mersininin kuru haldeki etanol ekstraktı ile yaş halinin aseton ekstraktı hem gram pozitif, gram negatif bakterilerine hem de maya suşlarına karşı çok iyi derecede aktivite gösterdiği bulunmuştur. Yaban mersininin kuru haldeki meyve ve yaprağının etanol ekstraktının, idrar yolu enfeksiyonları, menenjit, peritonit gibi hastalıklara neden olan gram pozitif bakterilerinden
Escherichia coli 'ye karşı çok etkili olduğu hatta standart ilaç olarak kullanılan ampisilinden daha iyi aktivite gösterdiği belirlenmiştir. Yaban mersininin yaş haldeki meyve ve yaprağının aseton ekstraktının ise maya suşlarından olan Candida albicans ve Saccharomyces cerevisiae'ye karşı çok iyi derecede etkili olduğu, mantar tedavisinde ilaç olarak kullanılan flukonazoldan çok daha iyi aktivite gösterdiği görülmüştür. Çözücüsü su ve dietil eter olan yaban mersini ekstraktları ise hiçbir test mikroorganizmasına karşı etki göstermemiştir.

Tablo 3. Bitki Estraktlarının Antimikrobiyal Aktivitesi ( $\mu \mathrm{g} / \mathrm{mL})$

\begin{tabular}{|c|c|c|c|c|c|c|c|c|c|c|}
\hline \multirow{2}{*}{ Bitki ekstraktı } & \multirow{2}{*}{ Çözücü } & \multicolumn{9}{|c|}{ Minimum İnhibisyon Konsantrasyon Değerleri $(\mu \mathrm{g} / \mathrm{mL})$} \\
\hline & & Ec & $Y p$ & $\mathrm{~Pa}$ & Sa & Ef & Bs & Ms & $\mathrm{Ca}$ & Sc \\
\hline Kuru meyve & Etanol & 1.9 & 7.8 & & & & & & 31.25 & 62.5 \\
\hline Kuru yaprak & Etanol & 3.9 & 15.6 & & & & & & 15.6 & 15.6 \\
\hline Yaş meyve & Aseton & & & & & & 0.78 & & 0.38 & 0.65 \\
\hline Yaş yaprak & Aseton & & & & & & 0.39 & & 0.78 & 0.71 \\
\hline Amp. & & 10 & 32 & $>128$ & 2 & 2 & $<1$ & & & \\
\hline Strep. & & & & & & & & 4 & & \\
\hline Flu. & & & & & & & & & $<8$ & $<8$ \\
\hline
\end{tabular}

Ec: E. coli ATCC 35218, Yp: Y. pseudotuberculosis ATCC 911, Pa: P. aeruginosa ATCC 10145, Sa: S. aureus ATCC 25923, Ef: E. faecalis ATCC 29212, Bs: B. Subtilis ATCC 6633, Ms: M. smegmatis ATCC607, Ca: C. albicans ATCC 60193, S. cerevisiae RSKK 251, Amp.: Ampisilin, Strep.: Streptomisin, Flu.: Flukonazol, (-): aktivite yok

Yaptığımız çalışmada doğal türde yaban mersininin, kuru meyve ve kuru yapraklarının yaş meyve ve yaş yapraklarına göre daha fazla antioksidan aktivite gösterdiği görülmüştür. İncelenen ekstratlar arasında yaban mersininin kuru meyvesinin etanoldaki ekstratının aktivitesinin en yüksek olduğu tespit edilmiştir.
Faria ve ark. (2005) tarafından yapılan araştırmada yaban mersininin \%50 lik etanol ekstraktları hazırlanmış ve toplam fenolik madde içeriği Troloks cinsinden 257.9 $\mathrm{mg} / 100 \mathrm{~g}$ şeklinde bulunmuştur. 
Burdulis et al. (2009) tarafından yapılan çalışmada, Litvanya'da yetişen yaban mersininin meyvesinin yüksek radikal temizleme ve antioksidan aktivitesine sahip olduğu ve de yaptıkları antimikrobiyal çalışmada ise test mikroorganizmaları içerisinde en yüksek aktiviteyi gram pozitif bakterilerden biri olan Escherichia coli'ye karşı gösterdiği bulunmuştur. Bu çalışmada, DPPH antioksidan sonuçlarına bakıldığında ise yaban mersininin kurutulmuş meyvesinin etanol ekstraktında, yine kurutulmuş yapraklarının etanol ve dietil eter ekstraktında en yüksek aktivite gösterdiği bulunmuştur. Aynı zamanda Burdulis ve arkadaşları tarafından yapılan çalışmaya benzer olarak yaban mersini ekstraktları Escherichia coli'ye karşı iyi derecede aktivite göstermiştir.

Bitkilerde çok farklı antioksidanlar bulunmaktadır ve antioksidan bileşenlerinin her birini tek tek ölçmek oldukça zordur. Bundan dolayı her özütün sahip olduğu antioksidan kapasitesini belirlemek için farklı testler uygulamak daha bilgi verici ve açıklayıcı olabilir (Tsai et al. 2002; Beretta et al. 2005; Huang et al. 2005). Bu araştırmada yaban mersininin yaş ve kurutulmuş örneklerinin toplam polifenol içerikleri, FRAP metodu ile antioksidan düzeyleri ve DPPH radikal temizleme aktivite sonuçları detaylı şekilde tespit edilmiştir. yaban mersininin kuru yaprak örneğinin su ekstraktındaki toplam polifenol içeriği $(19.484 \pm 1.85 \mathrm{mg}$ gallik asit/g numune) ve FRAP metoduna dayalı antioksidan değeri (652.049 $\pm 49.439 \mu \mathrm{mol}$ Troloks /g numune) en yüksek bulunmasına rağmen kuru yaprak etanol ekstraktının DPPH radikal temizleme gücü daha yüksek bulunmuştur. $\mathrm{Bu}$ nedenle kuru yaprak örneklerinde farklı oranlarda etanol - su karışımı kullanılarak yapılacak ekstraksiyon işlemleriyle antioksidan etkinin arttırabileceği düşünülmektedir.

Ünal ve ark. (2008) tarafından yapılan bir çalışmada, Türkiye'de tıpta uygulaması olan bazı bitkilerin antioksidan aktiviteleri, aseton, etanol, su gibi değişik çözücüler kullanarak belirlenmiştir. Elde edilen verilere göre çözücüsü su olan bitki ekstraktının serbest radikal süpürme etkinliği, çözücüsü etanol ve aseton olan ekstraktlarına göre daha yüksek çıktığı bulunmuştur. Bizim çalışmamızda ise kuru meyve, kuru yaprak ve yaş meyvede etanolik ekstraktlar, yaş yaprakta ise aseton ekstraktı daha yüksek sonuç vermiştir. Bitkilerde var olan etken maddelerin kullanılan çözücüye bağlı olarak değiştiği görülmüştür.

Silva et al. (2013) tarafından yapılan bir çalışmada İspanya'da yetişen yine üzümsü bir meyve türü olan yüksek boylu mavi yemiş (Vaccinium corymbosum)'in kurutulmuş meyve ve yaprağı ekstraktlarında antimikrobiyal aktivite araştırımış ve yaprak ekstraktlarının meyve ekstraktlarına göre daha iyi aktivite gösterdiği bulunmuştur. Bu çalışmada ise yaban mersininin ister kurutulmuş ister yaş halinin ekstraktı olsun; hem meyvesinde hem de yaprağında iyi derecede antimikrobiyal aktive olduğu görülmüştür.

\section{KAYNAKLAR}

Abay E (2006) Bazı Bitkilerin Ekstraktlarının Antimikrobiyal Etkilerinin Disk Difüzyon Yöntemiyle Araştırılması, Yüksek Lisans Tezi, Kars.

Akagün G (2009) Alabaş (Brassica oleracea var. Gongylodes) Bitkisinin Antioksidan Aktivitesinin İncelenmesi, Yüksek Lisans Tezi, Edirne.

Akkuş i (1995) Serbest radikaller ve fizyopatolojik etkileri, Mimoza Yayınları, Konya.

Almaraz N, Campos M, Avila J.A, Naranjo N, Herrera J, and Gonzalez L.S (2007) Antioxidant activity of polyphenolic extract of monofloral honeybee collected pollen from mesquite (Prosopis juliflora, Leguminosae). J Food Compos Anal. 20(2): 119-24.

Atalay M, Gordillo G, Roy S, Rovin B, Bagchi D, Bagchi M, and Sen C.K (2003) Anti-Antigionic Property of Edible Berry in a Model of Hemangioma. FEBS Letters 544: 252-257.

Bauer A.W, Kırbyrby W.M.M, Sherrıs J.C, and Turck M (1966) Antibiotic susceptibility testing by a standardized single disk method. Am. J. clin. Pathol 45: 493- 496.

Benzie Iff, Strain Jj (1996) The ferric reducing ability of plasmav (FRAP) assay a measure of "Antioxidant Power": The FRAP Assay. Analytical Biochemistry 239: 70-76.

Beretta G, Granata P, Ferrero M, Orioli M, Facino R.M (2005) Standardization of antioxidant properties of honey by a combination of spectrophotometric/fluorimetric assays and chemometrics. Analytica Chimica Acta 533(2): 185-191.

Bradshaw L.J (1992) Laboratory of microbiology, 4th edn, Saunders College Publishing, USA, pp 435.

Bravo L (1998) Polyphenol chemistry, dietary sources, metabolism and nutritional significance, Nutr. Rev. 56: 317-333.

Burdulis D, Sarkınas A, Jasutiene I, Stackeviciene E, Nicolajevas L, Janulis V (2009) Comparative Study Of Anthocyanın Composition, Antimicrobial And Antioxidant Activity In Bilberry (Vaccinium Myrtillus L.) And Blueberry (Vaccinium Corymbosum L.) Fruits. Acta Poloniae Pharmaceutican Drug Research 66(4): 399-408.

Collins C.H, Lyne P.M, and Grange J.M (1989) Microbiological methods. 6th edn, Butterworths, London, pp 410. 
Çelik H (2006) Karadeniz Bölgesindeki asitli topraklar için mükemmel bir meyve, likapa (yaban mersini). Çiftçi Dünyası Of Ziraat Odası Yayın Organı 2(2): 2-5.

Evers D.L, Chao C.F, Wang X, Zhang Z.G, Huong S.M, and Huang E.S (2005). Human cytomegalovirus-inhibitory flavonoids: studies on antiviral activity and mechanism of action. Antiviral Res. 68(3): 124-34.

Faria A, Oliveira J, Neves P, Gameiro P, Santos-Buelga C, Freitas V (2005) Antioxidant properties of prepared blueberry (Vaccinium myrtillus) extracts. Journal of Agricultural and Food Chemistry 53(17): 6896-6902.

Frankel E.N, Meyer A.S (2000) The problems of using one-dimensional methods to evaluate multifunctional food and biological antioxidants. Journal of the Science of Food and Agriculture 80(13): 1925-1941.

Harris G.K, Qian Y, Leonard S.S, Sbarra D.C, and Shi X.L (2006). Luteolin and chrysin differentially inhibit cyclooxygenase- 2 expression and scavenge reactive oxygen species but similarly inhibit prostaglandin-E2 formation in RAW 264.7 cells. J Nutr. 136(6): 1517- 1521.

Huang D, Ou B, Prior R.L (2005) The chemistry behind antioxidant capacity assays. Journal of agricultural and food chemistry 53(6): 1841-1856.

Hussain T, Arshad M, Khan S, Satar H, Qureshi MS (2011) In Vitro Screening of Methanol Plant Extracts for Their Antibacterial Activity. Pak. J. Bot. 43: 531-538.

Janovska D. Kubikova K, Kokoska L (2003) Screening for Antimicrobial Activity of Some Medicinal Plants Species of Traditional Chinese Medicine. Czech J. Food Sci. 21: 107-110.

Kırca A, Bilişli A, Demirel N.N, Turhan H. ve Arslan E (2007) Çanakkale florasındaki bazı tıbbi ve aromatik bitkilerin antioksidan ve antimikrobiyal aktiviteleri. TÜBiTAK Proje No: 1040292. Çanakkale.

Kil H.Y, Seong E.S, Ghimire B.K, Chung M, Kwon S.S, Goh E.J, Heo K, Kim M.J, Lim J.D, Lee D, Yu C.Y (2009) Antioxidant and antimicrobial activities of crude Sorghum ekstract, Food Chemistry 115: 12341239.

NCCLS National Committee for Clinical Laboratory Standarts. (2000). Performance standarts for antimicrobial disc susceptility tests; 7 ed. Approved Standart M2-A7 NCCLS, Pennsylvania.

Silva S, Costa E.M, Pereira M.F, Costa M.R, Pintado M.E (2013) Evaluation of the antimicrobial activity of aqueous extracts from dry Vaccinium corymbosum extracts upon food microorganism, Food Control 34: 645-650.

Singh B, Dutt N, Kumar D, Singh S, Mahajan R (2011) Taxonomy, Ethnobotany and Antimicrobial Activity of Cro-ton bonplandianum, Euphorbia hirta and Phyllanthus fraternus. J. Adv. Develop. Res. 2: 21-29.

Singleton V, Rossi J.A (1965) Colorimetry of total phenolics with phosphomolybdic-phosphotungstic acid reagents. American journal of Enology and Viticulture, 16(3): 144-158.

Toroglu, S (2007) In vitro antimicrobial activity and antagonistic effect of essential oils from plant. species., J. environ. Biol. 28: 551-559.

Tsai P.J, McIntosh J, Pearce P, Camden B, Jordan B.R (2002) Anthocyanin and antioxidant capacity in Roselle (Hibiscus sabdariffa L.) extract. Food Research International, 35(4): 351-356.

Ünal E (2006) Türkiye florasında doğal olarak yetişen bazı bitki türlerinin antimikrobial ve antioksidan aktivitelerinin incelenmesi, Yüksek Lisans Tezi, Kırıkkale.

Ünal E. L, Mavi A, Kara A.A, Cakir A, Şengul M, Yildirim A (2008) Antimicrobial and antioxidant activities of some plants used as remedies inTurkish medicine, Pharmaceutical Biology 46: 207-224.

Wollgast J, and Anklam E (2000) Review on Polphemols in Theobroma Cacao, Changes in Composition During the Manufacture of Choconate and Methodology for Identication and Quantification. Food Res Int. 33: 423-447.

Wu X, Cao G, and Prior R.L (2002) Absorption and Metabolism of Anthocyanins in Elderly Women after

Consumption of Elderberry or Blueberry. The Journal of Nutrition, ProQuest Agriculture Journals 132(7): 1865-1871. 